\title{
A QUALITATIVE STUDY OF THE CONTINUING PROFESSIONAL DEVELOPMENT ACTIVITIES OF THE CHINESE PRIVATE KINDERGARTEN TEACHERS' PROFESSIONAL COMPETENCE
}

\author{
XIAOJING LIU \\ Center for Educational Science and Technology, \\ Beijing Normal University at Zhuhai \\ No.18, Jinfeng Road, Tangjiawan, Zhuhai City, \\ Guangdong Province, 519087, P.R. China \\ E-mail address: xjliu@bnu.edu.cn \\ ORCID: http://orcid.org/0000-0002-9355-8075 \\ YULONG LI (corresponding author) \\ Department of General Education, \\ Faculty of Humanities and Social Sciences, \\ City University of Macau, Avenida Padre Tomás Pereira, \\ Taipa, Macau SAR, P.R. China \\ E-mail address: marvinli@cityu.mo \\ ORCID: https://orcid.org/0000-0002-0348-8035
}

\begin{abstract}
Aim. The number of kindergartens is swelling in China, and that of private kindergartens in particular. The quality of teaching in the latter is positively linked to the levels of teachers' professional competence. Thus, to enhance the teaching quality in private kindergartens, strengthening teacher's professional competence is one of the vital approaches. Teacher's professional competence can be enhanced via effective CPD activities. Therefore, this study aims to explore the types and content of CPD activities for Chinese private kindergarten teachers.

Methods. A qualitative approach was adopted in this research. 18 kindergarten teachers were selected as participants from three private kindergartens in Shenzhen. Data was collected by semi-structured interview from 18 teachers.

Results and conclusion. The findings showed that the school-based CPD activities are valued by most private kindergarten teachers. Furthermore, this study found that CPD activities can help private kindergarten teachers to be more inclusive and positive in teaching. They enabled teachers to acquire knowledge and skills that are relevant to child care and development, teaching, as well as cooperation with colleagues and children's parents.
\end{abstract}


Practical application. The research findings presented herein have significant implications for the knowledge base of private kindergarten teachers' CPD in China. It also has implications for the practice that is relevant to private kindergarten teachers, principals and policy makers.

Key words: CPD, Professional Competence, Private Kindergarten Teachers

\section{INTRODUCTION}

$\mathrm{T}$ his decade it has become increasingly evident that there are pressing needs to improve the support in early childhood education (ECE) and provide for the development of children from different families. Nowadays, the number of kindergartens in China is swelling, particularly the private ones, taking up two thirds of ECE institutions nationwide. Although the number of private kindergartens has increased dramatically, their unsatisfactory teaching quality that is closely related to the shortage of professional teachers remains a concern for the society. In this context, some Chinese educators have moved their attention as to how to improve the quality of ECE via enhancing teachers' professional competence. It has been found that the quality of ECE programs is positively linked to the levels of teachers' professional competence (Hu et al., 2017). In other words, in order to enhance the quality of ECE programs, strengthening teacher's professional competence is one of the vital approaches. According to Katrina McChesney and Jill Aldridge (2018), teacher's professional competence can be enhanced via effective CPD activities, which aim to improve their professional development. However, studies of CPD activity types and content as well as its impact on private kindergarten teachers are limited in China. Therefore, this study focuses on this field and explore the impact of CPD activities on Chinese private kindergarten teachers' professional competence.

\section{LITERATURE REVIEW}

\section{Types of kindergarten teachers' CPD activities in China}

According to Bi Ying Hu and Judit Szente (2009), CPD activities are significant for teaching effectiveness. They have the potential to enhance teachers' competence by equipping them with pedagogical knowledge and providing teaching skills that help them increase their instructional effectiveness. The current study categorised multiple CPD activities for Chinese kindergarten teachers into three groups: kindergarten-based (school-based) CPD activities (Zhang \& Wong, 2017), external expert supported CPD activities (Lin, 2012), and teachers' self-learning CPD activities (Keller-Schneider, 2014). Based on the relevant literature, in total, 13 types of CPD activities for kindergarten teachers are listed in this study. 
Table 1

Types of CPD activities

\begin{tabular}{l} 
Types of CPD activities \\
\hline Kindergarten-based CPD activities \\
\hline CPD activities based on kindergarten teachers' practical working context \\
\hline 1. To consult with experienced teachers through mentoring; \\
2. To observe the methods in the experienced teachers' daily teaching activities; \\
3. To set a mentoring plan and share teaching experience; \\
4. To do collective lesson preparation; \\
5. To share teaching and learning experiences when prepare their lessons; \\
6. To consult with lesson teaching records and materials in school; \\
7. To participate in class observation activities; \\
\hline CPD activities conducted in the other kindergarten contexts \\
\hline 8. To participate in school visits; \\
9. To do collaborative teaching with teachers in other schools; \\
\hline External expert supported CPD activities \\
\hline 10.To participate in seminars; \\
11.To participate in certificate courses; \\
\hline Teachers' self-learning CPD activities \\
\hline 12.To write academic articles; \\
13.To do extracurricular reading.
\end{tabular}

A summary of these activities was used as guidance to explore the factual situation of CPD activities participated in by teachers in private kindergartens in this research.

\section{Content of kindergarten teachers' CPD activities}

CPD activities cannot make an impact on teachers without effective and appropriate learning content (Timperley et al., 2008). The contents of CPD activities should be associated with the goal of kindergarten teachers' CPD. In this section, the contents of CPD activities focus on three aspects that are relevant to teachers' work on children's development, teaching and collaborating with children's parents.

Firstly, children's development refers to the biological, psychological and emotional changes that occur in children between birth and the end of adolescence (Cole, Cole, \& Lightfoot, 2005). It is a continuous process with a predictable sequence yet having a unique course for every child (Keenan, Evans, \& Crowley, 2016). Nowadays, enhancing children's development has been considered as a vital aim in ECE, and children's development can be influenced by the quality of their care and education from teachers.

Kindergarten teachers may be the first important non-family adults with whom children develop relationships. They play roles as both caregivers and educators by providing young children with warmth and nurture (Bullock, Coplan, \& Bosacki, 2015). If teachers acquire more knowledge or skills on children's development, they should be able to understand children's develop- 
mental stages better (Spodek, 1973). Furthermore, teachers' understanding of children's development also can influence their responses or attitude to children's classroom behaviour, as well as their teaching style and classroom decisions (Rentzou \& Sakellariou, 2011). Considering the importance of the content on children's development, it is necessary for teachers to learn from their CPD activities. In line with this consideration, the current study aims to explore what kinds of content regarding children's development should be included in the CPD activities for private kindergarten teachers.

Secondly, there are different teaching methodologies in ECE, of which the most famous ones are, i.a., Frobel approach, Montessori approach, the Project approach, Waldorf approach, Reggio Emillia approach, and the High/scope approach (Hoskins \& Smedley, 2016). By adopting different approaches, teachers' roles will be different. For instance, Lissanna Follari (2007) indicated that the teachers who follow the Montessori approach need to carefully prepare the learning environment and know how to use didactic materials; however, the teachers who adopt the project approach should focus on their responsibility in guiding children to explore, and to help children uncover misconceptions. Kindergarten teachers can follow these different teaching methodologies, and they play a significant role in teaching (Oleson \& Hora, 2014). Therefore, a goal of their CPD is, thus, to help them understand their role in teaching and enhance their teaching quality.

Thirdly, in addition to learning how to teach in ECE, learning in the context of school-family cooperation is also significant for kindergarten teachers' CPD. According to Elena Nitecki (2015), school and family play an equally significant role in enhancing children's diversified development. The quality of relationship that young children experience early on with parents can impact their later academic performance and achievement, as well as contribute to their prosocial behaviour. Therefore, kindergarten teachers are in need of parental support for sustaining the psychological, academic, and social development of their students (Vlasov \& Hujala, 2017). If the parents do not support kindergarten teachers or they stand against the attempts of the teachers, the expected behavioural changes are very hard to achieve and the children are hard pressed to attain an expected developmental level (Savas, 2012). The above-mentioned are centred on the content of CPD activities for kindergarten teachers. Based on these, the current study hopes to explore what kinds of content are valued by private kindergarten teachers.

\section{RESEARCH METHOD}

\section{Research setting and participants}

Shenzhen was selected as the research site as private kindergartens play a dominant role in the provision of ECE in this city. 98\% of preschoolers and $97 \%$ of ECE teachers in the city are under the private school system, which accounts for $90 \%$ of the total number of kindergartens (Wang, Hong, \& Pang, 2015). Furthermore, the concern of teacher's CPD and the teaching quality of private kindergartens has been raised in Shenzhen (Guo, 2015). Thus, Shenzhen was selected as the research setting 
for this study. Furthermore, the selection of kindergartens in Shenzhen was based on a convenient sampling method. This means that researchers choose sites they can easily get access to in order to conduct the research or select research participants (Muijs, 2012). In line with this, three private kindergartens with which the researcher was familiar with were selected, and they were given the name codes of $\mathrm{A}, \mathrm{S}$, and $\mathrm{Y}$.

In terms of the selection of participants, the study applied a purposive sampling method. 18 kindergarten teachers who had participated in CPD activities were selected (6 teachers from each case study kindergarten). Moreover, this study considered that teachers' responses to CPD activities and their competence in applying newly acquired knowledge and skills in the classroom may have resulted in variations due to their different career stages. According to Paul Burden (1982), teachers have three sequential teacher career stages: survival, the first year; adjustment, years 2-4; and maturity, the fifth year and beyond. In line with this theory, the current study categorised private kindergarten teacher participants into two groups: beginner teachers or new teachers (NT) and senior teachers (ST). Beginner teachers included teachers with less than five years of teaching experience, who were at the survival and adjustment stage in their teaching. Senior teachers included teachers with five or more years of teaching experience, who were at the mature stage in their teaching. Please see the following participants' demographic information form.

Table 2

Participants' demographic information

\begin{tabular}{ccccc}
\hline $\begin{array}{c}\text { Beginning } \\
\text { Teacher (NT) }\end{array}$ & Sex & Age & Qualification & $\begin{array}{c}\text { Teaching } \\
\text { Experience }\end{array}$ \\
\hline ANT1 & F & $20-25$ & College & 4 years \\
ANT2 & F & $20-25$ & College & 4 years \\
ANT3 & F & $20-25$ & College & 2 years \\
ANT4 & F & $20-25$ & College & 1 year \\
SNT1 & F & $31-35$ & Undergraduate & 2 years \\
SNT2 & F & $20-25$ & College & 3 years \\
SNT3 & F & $20-25$ & College & 5 months \\
SNT4 & F & $20-25$ & College & 5 months \\
YNT1 & F & $20-25$ & Undergraduate & 2 months \\
YNT2 & F & $20-25$ & College & 6 months \\
YNT3 & F & $20-25$ & College & 3 years \\
YNT4 & F & $20-25$ & College & 3 years \\
\hline Senior & & & & Teaching \\
Teacher $($ ST $)$ & Sex & Age & Qualification & Experience \\
\hline AST1 & F & $26-30$ & College & 9 years \\
AST2 & F & $20-25$ & College & 5 years \\
SST1 & F & $26-30$ & College & 6 years \\
SST2 & F & $31-35$ & College & 5 years \\
YST1 & F & $31-35$ & Undergraduate & 9 years \\
YST2 & F & $35-40$ & College & 15 years \\
\hline SNT & & &
\end{tabular}

Source: own research. 


\section{Data Collection and analysis}

Semi-structured interviews were used as the data collection method for the 18 teachers. According to Owen Doody and Maria Noonan (2013), semi-structured interviews can be flexible, with open-ended questions and the chance to explore issues that arise spontaneously in qualitative studies. They also can encourage depth and vitality, which help new concepts to emerge in qualitative studies (Dearnley, 2005). The interview questions were with reference to the summarised types and contents of CPD activities, and all the teachers were allowed to share their CPD learning experience freely. In addition, the research aim and the importance of confidentiality were explained to all 18 teacher participants before being interviewed. With their consent, interviews were conducted individually in their kindergartens' meeting rooms and lasted for approximately one hour. All interviews were recorded using a tape-recorder and transcribed without mentioning the participants' names and distinguishing features.

In terms of data analysis, the inductive content analysis method was used in this study. The inductive approach can be used when former knowledge about the phenomenon is limited or if this knowledge is fragmented (Lauri \& Kynga s, 2005). According to Murray Thomas (2003), inductive content analysis approaches are intended to aid the understanding of the meaning of complex data through the development of summary themes or categories from raw data.

In this study, it was found that the knowledge of CPD activity types and contents for private kindergarten teachers in China was limited and un-systematic. Therefore, this study organised the raw data collected from the 18 teachers' answers to the types and contents of the CPD activities from their interview data. Furthermore, through inductive analysis which included the process of open coding, creating categories and abstraction (Chinn \& Kramer 1999), the themes on the key types and contents of the CPD activities emerged. Please see examples shown in Table 3.

Table 3

The themes on the key types and contents of the CPD activities

\begin{tabular}{|c|c|c|}
\hline Code & Category & Theme \\
\hline $\begin{array}{l}\text { I used to participate in an English training } \\
\text { course in the CPD activities, and I } \\
\text { learned that it is useful to teach children } \\
\text { by providing an English experimental } \\
\text { platform for them. (SST2) }\end{array}$ & $\begin{array}{l}\text { English teaching } \\
\text { method }\end{array}$ & Teaching \\
\hline $\begin{array}{l}\text { I have learned a new teaching method in } \\
\text { CPD activity, which is called Montessori } \\
\text { teaching method. I think this teaching } \\
\text { method is very practical and I like to } \\
\text { apply it in my teaching process. (ANT2) }\end{array}$ & $\begin{array}{l}\text { Montessori } \\
\text { teaching method }\end{array}$ & \\
\hline
\end{tabular}




\section{FINDINGS}

It was found that there were six types of CPD activities reported by most private kindergarten teacher participants in this study. The contents of the CPD activities were focused on teaching, management, childcare and child development and school-family cooperation. The following paragraphs describe these findings in detail.

\section{Key types of CPD activities for private kindergarten teachers}

It was found that among the 13 types of CPD activities summarised in this study, six of them were reported by over half of the teacher participants (involving 12 beginning teachers and 6 experienced teachers). Teachers admitted to participate in the activities that they reported, and these CPD activities have profound impacts on their professional competence. These key CPD activities were listed in Table 4. Over half of the interviewees mentioned the six CPD activities, which formulates the importance of them in enhancing teachers' professional competence in the current context. Furthermore, it was found that all of the above-mentioned activities belonged to the kindergarten-based CPD activities. Therefore, this study further analysed the teachers' perceptions on kindergarten-based CPD activities.

Table 4

Six CPD activities reported by private kindergarten teachers

\begin{tabular}{ll}
\hline Types of CPD activities & No. of teachers \\
\hline $\begin{array}{l}\text { To share teaching and } \\
\text { learning experiences on } \\
\text { lesson studies }\end{array}$ & $\begin{array}{l}\text { 8 beginning teachers (ANT2, ANT4, SNT1, } \\
\text { SNT2, SNT3, SNT4, YNT3, YNT4) and 6 } \\
\text { experienced teachers (AST1, AST2, SST1, SST2, } \\
\text { YST1, YST2). }\end{array}$ \\
$\begin{array}{ll}\text { To consult with experienced } \\
\text { teachers through mentoring }\end{array}$ & $\begin{array}{l}\text { SNT1, SNT2, SNT3, SNT4, YNT2, YNT3, YNT4) } \\
\text { and 3 experienced teachers (AST2, SST1, YST2). }\end{array}$ \\
$\begin{array}{l}\text { To observe the methods from } \\
\text { the experienced teachers' } \\
\text { daily teaching activities }\end{array}$ & $\begin{array}{l}\text { SNT1, SNT2, SNT3, SNT4, YNT2, YNT3) and 4 } \\
\text { experienced teachers (AST1, AST2, SST1, YST1). }\end{array}$ \\
$\begin{array}{l}\text { To set a mentoring plan and } \\
\text { sharing teaching experience }\end{array}$ & $\begin{array}{l}\text { YNT4) and 5 experienced teachers (AST1, AST2, } \\
\text { SST1, YST1, YST2). }\end{array}$ \\
$\begin{array}{l}\text { To participate in class } \\
\text { observation activities }\end{array}$ & $\begin{array}{l}\text { 7 beginning teachers (ANT1, ANT4, SNT1, } \\
\text { SNT2, SNT3, SNT4, YNT4) and 4 experienced } \\
\text { teachers (AST1, SST1, YST1, YST2). }\end{array}$ \\
& 5 beginning teachers (ANT2, ANT4, SNT2, \\
To participate in school visits & AST2, SST1, SST2, YST2). \\
\hline
\end{tabular}


It was found that kindergarten-based CPD activities were confirmed as vital approaches in enhancing private kindergarten teachers' professional competence from two perspectives. First, teachers indicated that they can learn more practical teaching methods from these activities. This could be seen from teacher YNT2's and ANT4's responses: "If I participated in kindergarten-based CPD activities, some experienced teachers can tell me how to teach or how to communicate with children in a particular way. They have sufficient experience and I think they are convincing" (YNT2).

Similarly, teacher ANT4 reported her learning of Montessori teaching methods from kindergarten-based CPD activities. She stressed such learning is useful for her practical teaching.

I usually participate in kindergarten-based CPD activities once a week or once a month. They are very effective, because they are more related to how to teach young children in detail. For example, I had never learned the Montessori mathematics teaching method or concepts; I feel they are very practical for my teaching when I learned them from kindergarten-based CPD activities. (ANT4)

In addition to enabling teachers to learn more practical teaching methods, kindergarten-based CPD activities were also considered to be effective due to their well-fitted combination with teachers' learning needs and contexts. Teacher AST1 provided an explanation. She said CPD activities provided in their kindergarten could take their school's real situation into consideration, which was helpful for teachers to teach or work at school.

I think kindergarten-based CPD activities are more appropriate for our practical instruction. Every kindergarten has a different situation. As a teacher, we should not ignore it... teachers' learning in CPD activities learning should be based on their kindergarten's teaching environment. (AST1)

ANT1 also claimed that kindergarten-based CPD activities were more relevant to their needs for teaching in the school: "The design and arrangement of kindergarten-based CPD activities can align with our learning needs. Such learning is more helpful for us to solve teaching problems, and that's why 70\% of our CPD activities are kindergarten-based CPD activities" (ANT1). In short, among the 14 CPD activities, there were six types in which more than $50 \%$ of the 18 teachers reported having participated in. Teachers placed higher value on kindergarten-based CPD activities as they could learn practical teaching methods in context. In the next section, findings on the contents of the CPD activities is illustrated.

\footnotetext{
Four aspects of core contents in CPD activities for private kindergarten teachers

Different content learned by teachers in their CPD activities may have different impact on their professional competences and practice. This section focuses on the core contents of CPD activities from teachers' interview responses. It was found that the content of $\mathrm{CPD}$ activities can be grouped into 13 categories. Based on this, this study further derived four organising themes: teaching, management, childcare and development, and school-family cooperation. The details can be seen in Table 5 .
} 
Table 5

Key contents of CPD activities

\begin{tabular}{ll}
\hline Themes & \multicolumn{1}{c}{ Categories } \\
\hline Teaching & 1. English teaching method \\
& 2. Montessori teaching method \\
3. Orff music teaching method & 4. "Corner" teaching method \\
5. Multimedia teaching method & 6. Subject research method \\
& 7. Classroom management \\
8. Daily activities management in \\
kindergarten \\
9. Environment creation and management \\
10. Child care knowledge and skills \\
11.Children's psychological and cognitive \\
theory \\
12.Children's communication and \\
encouragement skills \\
13. Communication and collaborationskills \\
with children's parents
\end{tabular}

Source: own research.

As previously discussed in the literature review, equipping kindergarten teachers with knowledge and skills in ECE teaching enabled them to fulfill their role in teaching and to improve their teaching quality. From this table, it can be seen that the first organising theme-teaching has covered a variety of content relevant to teaching, especially teaching methods, such as English teaching method, Montessori teaching method, or Orff music teaching method. The second theme included the content relevant to management. Attending CPD activities enabled teachers to facilitate their classroom management. It also allowed them to learn how to manage their teaching environment, as well as children's daily activities in kindergartens. The third theme - child care and development was derived from the content relevant to knowledge and skills on childcare, child psychology and health, as well as child communication and encouragement. To some extent, learning about this content aims to facilitate teachers' competence in taking better care of children, identifying children with developmental problems, and providing appropriate support for teachers to better communicate with children. In addition, the fourth theme - schoolfamily cooperation in this table was based on the content that teachers learned on communication and collaboration skills with children's parents. Kindergarten teachers need parental support for sustaining the psychological, social and academic development of children and for maintaining and controlling children's behaviour outside school (Savas, 2012). If the parents do not support teachers or they stand against the attempts of teachers, the expected behavioural changes are very hard to achieve and the children will be hard pressed to attain an expected developmental level (Savas, 2012). This study proved 
that content of the CPD activities for private kindergarten teachers involved in school-family cooperation is important.

In short, this table abstracted the core content in private kindergarten teachers' CPD activities. It covered four aspects: teaching, management, child care and development and school-family cooperation., This study found that management skills is now given more emphasis in the CPD learning contents for kindergarten teachers.

\section{DISCUSSION}

\section{Understanding the types of CPD activities valued by private kindergar- ten teachers}

This study found that private kindergarten teachers placed higher value on kindergarten-based CPD activities rather than other CPD activities, as they could learn practical teaching methods in context. These are the main types of CPD activities participated in by teachers in private kindergartens. Based on these findings, three points are discussed and used to explain why kindergarten-based CPD activities has become so significant for private kindergarten teachers' CPD.

Firstly, this study considered that kindergarten-based activities play the main role in private kindergarten teachers' CPD and were relevant to their effectiveness in addressing teachers' learning needs. This point is consistent with some previous studies in this field (Qin \& Yang, 2012). These studies indicated that kindergarten-based CPD activities are effective because they can integrate teachers' learning needs, teacher's practical teaching problems and kindergarten's educational resources together. Based on these, attending to kindergarten-based CPD activities can provide more practical support for teachers, allowing them to enhance their teaching competence in kindergartens. By contrast, it has been claimed that some external expert supported CPD activities, for example, seminars, are usually carried out with limited consideration for kindergarten teachers' learning needs (Croft et al., 2010). Hence, it is difficult for teachers to turn what they have learned from these kinds of CPD activities into practice. Therefore, when comparing these different CPD activities, it is not difficult to understand why kindergarten-based activities play the key role for private kindergarten teachers' CPD.

Secondly, this study indicated that the importance of kindergarten-based CPD activities is relevant to the expansion of private kindergartens and their teaching quality. As previously mentioned in the introduction, the number of private kindergartens is more than two times of the number of public kindergartens due to stimulation by policy and the socialist market economy. However, teaching quality in these private kindergartens seems to still be difficult to guarantee. It was found that teachers at private kindergartens are relatively inexperienced and lack professional teaching competence. Against this background, in order to cater for the needs of parents and the market, many pri- 
vate kindergartens have started to take more responsibility in teacher training so that their teachers' professional competence can be enhanced. As a result, kindergarten-based CPD activities have gradually become the main types for teachers working in private kindergartens.

Thirdly, this study considered that kindergarten-based CPD activities play a vital role for teachers' professional development which may also be relevant to the changes of the national CPD training service for teachers. Nowadays, the national CPD training service for kindergarten teachers is in the process of improvement (Zhou, 2016). Therefore, the majority of private kindergarten teachers may learn to enhance their professional competence at their own workplaces. In China, the traditional CPD training service mainly takes the form of direct government provision, and teachers' training at all levels is carried out in designated training institutions (Zhou, 2016). However, with the change and improvement of the teacher training service system, the way of the central government guiding and providing teacher training services has changed. Nowadays, the government is encouraging school-based training and teachers' self-learning for enhancing kindergarten teachers' competence (Zhou, 2016). At the same time, it has also tried to use multiple approaches to provide training services for teachers' CPD. These approaches include: (1) the government providing training services directly; and the governmental teacher training institution employing training specialists to organise teacher's CPD training; (2) the government purchasing training services to train teachers via colleges and universities by calling for tenders; (3) voluntary services, such as some education associations providing free training for teachers CPD; (4) sending teachers to education developed areas to learn through the governmental agreement; and (5) government subsidies, such as providing funding for teachers to gain a higher education degree. Therefore, it can be seen that the teacher training system is becoming more comprehensive. However, there is still a long way to go to achieve this comprehensive training system for teacher's professional development. Within this context, kindergarten-based CPD activities play a major role to enhance the large number of private kindergarten teachers' competence at the current stage.

In short, the aforementioned discussion explores the reason for which kindergarten-based CPD activities are the main types of CPD activities private kindergarten teachers participate in. In the next section, the core contents of $\mathrm{CPD}$ activities for private kindergarten teachers is discussed.

\section{Understanding on the four aspects of core contents in CPD activities}

Effective and appropriate CPD content plays a significant role for enhancing kindergarten teachers' competence. In the current study, it was found that the content of private kindergarten teachers' CPD activities mainly covered four aspects: teaching, management, child care and development, and schoolfamily cooperation. This section discusses these four aspects in detail.

Firstly, the results on the content of CPD activities show that private kindergarten teachers' $\mathrm{CPD}$ has focused on transmitting teaching methods, skills and 
concepts. This is consistent with Ivelisse Martinez-Beck and Martha Zaslow's (2006) study, which stressed that the goal of CPD activities is to help teachers to understand their role in teaching and to enhance their teaching quality. Furthermore, the findings of the current study are also similar to those of Bruce Joyce and Beverley Showers (2002). They indicated that the content of CPD activities should focus on instructional methods and knowledge, which may make the teachers obtain better understanding of their class. Therefore, it can be seen that it is a constant task in teachers' CPD activities to enhance the quality of teaching through equipping private kindergarten teachers with different teaching methods and knowledge.

Secondly, this study also shows that the content of private kindergarten teachers' CPD activities has involved management, such as teaching environment management and children's daily activities management. This finding is different from some previous studies which claimed that kindergarten teachers' CPD activities have paid more attention to emphasising teaching methods and skills (Aelterman et al., 2016). It proved that the current CPD activities for private kindergarten teachers have also stressed the significant role of management in different aspects in ECE. The reasons for this situation may be relevant to the following three aspects: a) effective management in the teaching environment and children's daily routines can facilitate teachers' teaching in kindergartens (Pianta, 2002); b) large class sizes in some Chinese private kindergartens cause their management in the teaching environments or in children's daily activities to still be weak. Therefore, to enhance teachers' competence in these aspects through CPD activities is an important task; c) the traditional role of kindergarten teachers in China is to help children's parents to take care and manage their children's daily behaviour (Fan, Nyland, \& Zeng, 2016). In line with this impact, teachers not only take the role as the teacher, but also the role of manager in their class. All of these can be used to explain why private kindergarten teachers' CPD activities involve a lot of content on management in class and children's daily routines.

Thirdly, the findings of this study indicate that private kindergarten teachers' CPD activities have paid attention to children's development, no matter physical or mental. In line with this, many teachers have learned the content of the knowledge and skills of child care, which are of benefit for them to advance children's physical development. Furthermore, teachers can also learn the content on children's psychological and cognitive theory. In addition, their CPD activities enable them to learn many skills to communicate with and encourage children. Based on learning this content, teachers can better enhance the psychological development of children. All of the above provide evidence to support some relevant studies (Coplan et al., 2015; Keenan et al., 2016). These studies stressed that enhancing children's development should be a vital task in ECE. Kindergarten teachers' CPD activities should improve teachers' competence in this aspect because teachers play the roles of both caregiver and educator which can profoundly influence children's development (Coplan et al., 2015; Keenan et al., 2016). 
Fourthly, the results on the CPD content can reflect the fact that private kindergarten teachers' CPD activities have realised the significant role of school-family collaboration in ECE. As a result, the content of school-family cooperation is included in many CPD activities, such as communication with children's parents, and inviting parents to participate in the kindergarten's teaching activities. To be more specific, learning the skills of communicating with children's parents have enabled teachers and parents to have a shared understanding on how to teach children. Based on this, teachers and parents may produce a better ECE in kindergartens. This finding is consistent with a study from Ahmet Cezmi Savas (2012), which emphasised that it is vital for teachers and parents to stand on one line to teach children. If parents stand out against the attempts of teachers, it is difficult to teach children effectively (Savas, 2012). Furthermore, learning the skills on how to invite children's parents to join in the kindergarten's teaching activities have also allowed teachers to facilitate collaboration between kindergartens and families. This finding can add evidence to support some previous studies in this field (Nitecki, 2015). These studies indicated that as parental education has a profound impact on young children's development, it is meaningful for teachers to encourage parents to join in their teaching activities in a planned way. Private kindergarten teachers are also in need of parents' support for sustaining the psychological, social and academic development of their students.

\section{CONCLUSION}

To summarise, this study found that campus-based learning are the main types of CPD activities which private kindergarten teachers participate. These CPD activities are gradually becoming a part of the comprehensive and multiple forms of CPD activities in China. They are more likely to consider the teachers' learning needs and teaching context. Furthermore, this study also found that the content of private kindergarten teachers' $\mathrm{CPD}$ activities is mainly relevant to teaching, management (on environment and children's daily activities), childcare and development as well as school-family cooperation. These results can reflect that private kindergarten teachers' CPD has focused on enhancing teaching quality so that various methods, skills and concepts relevant to teachers' teaching were involved in their CPD activities. Learning this content may enable teachers' CPD to become more multi-dimensional. To a great extent, this study updates the knowledge base of school-based approaches for private kindergarten teachers' CPD in China, and it also provides a clear description on the valuable CPD contents that teachers learned. Based on these, it is helpful for teachers to better reflect on their kindergarten-based CPD activities; for principals to reasonably adopt activities to arrange the plans for teacher's CPD; for educators and researchers to gain a comprehensive and deep understanding of private kindergarten teachers' CPD activities; and for policy makers to reconsider to how to support private kindergartens to organise their kindergarten-based CPD activities for enhancing teaching quality. 


\section{ACKNOWLEDGMENTS}

We would like to express our sincere gratitude to professor Yee Fan Sylvia Tang and dr Junjun Chen from The Education University of Hong Kong for their tremendous support and advice.

\section{REFERENCES}

[1] Bullock, A., Coplan, R. J., \& Bosacki, S. (2015). Exploring links between early childhood educators' psychological characteristics and classroom management self-efficacy beliefs. Canadian Journal of Behavioural Science/Revue canadienne des sciences du comportement, 47(2), 175-183.

[2] Burden, P. R. (1982). Developmental Supervision: Reducing Teacher Stress at Different Career Stages. (Unpublished Dissertation). Kansas State University.

[3] Chinn, P. L., \& Kramer, M. K. (1999). Theory and nursing integrated knowledge development. Retrieved May 3, 2018 from: https:/ / philpapers.org/rec/CHITAN

[4] Cole, M., Cole, S. R., \& Lightfoot, C. (2005). The development of children. London: Macmillan.

[5] Coplan, R. J., Bullock, A., Archbell, K. A., \& Bosacki, S. (2015). Preschool teachers' attitudes, beliefs, and emotional reactions to young children's peer group behaviors. Early Childhood Research Quarterly, 30, 117-127.

[6] Croft, A., Coggshall, J., Dolan, M., \& Powers, E. (2010). Job-embedded professional development: What it is, who is responsible, and how to get it done well (Issue Brief). Washington, DC: National Comprehensive Center for Teacher Quality.

[7] Dearnley, C. (2005). A reflection on the use of semi-structured interviews. Nurse Researcher, 13(1), 19.

[8] Doody, O., \& Noonan, M. (2013). Preparing and conducting interviews to collect data. Retrieved May 3, 2018, from https://ulir.ul.ie/handle/10344/5588

[9] Fan, X., Nyland, B., \& Zeng, X. (2016). What knowledge and skills do Chinese kindergarten, teachers need in a time of reform: Director's perspectives. Asia Pacific Journal of Early Childhood Education Research, 10(3), 27-48.

[10] Follari, L. M. (2007). National Association for the Education of Young Children: Defining best practices. In: L. Follari. (Ed.), Foundation and best practices in early childhood education (pp. 104124). Boston: Pearson.

[11] Guo, Y. (2015). Perspectives on curriculum and pedagogy in a private kindergarten in China (Doctoral dissertation, Sheffield Hallam University), United Kingdom.

[12] Hoskins, K., \& Smedley, S. (2016). Life history insights into the early childhood and education experiences of Froebel trainee teachers 1952-1967. History of Education, 45(2), 206-224.

[13] Hu, B. Y., \& Szente, J. (2009). Exploring the quality of early childhood education in China: Implications for early childhood teacher education. Journal of Early Childhood Teacher Education, 30(3), 247-262.

[14] Joyce, B. R., \& Showers, B. (2002). Student achievement through staff development. National College for School Leadership. Retrieved May 3, 2018, from: https://www.unrwa.org/sites/default/ files/joyce_and_showers_coaching_as_cpd.pdf

[15] Keenan, T., Evans, S., \& Crowley, K. (2016). An introduction to child development. New York: Sage.

[16] Keller-Schneider, M. (2014). Self-Regulated Learning in Teacher Education-The Significance of Individual Resources and Learning Behaviour. Australian Journal of Educational \& Developmental Psychology, 14, 144-158.

[17] Lauri, S., \& Kynga s, H. (2005). Developing Nursing Theories. Werner Söderström. Vantaa: Dark Oy.

[18] Lin, X. (2012). Dui youeryuan jiaoshi duiwu jianshe de sikao - yi xiamenshi weili.[A reflection on the teachers in kindergartens - take the example of Xiamen]. Jichu jiaoyu, 53-59.

[19] Martinez-Beck, I., \& Zaslow, M. (2006). Introduction: The Context for Critical Issues in Early Childhood Professional Development. Baltimore: Paul H Brookes Publishing.

[20] McChesney, K., \& Aldridge, J. M. (2018). A review of practitioner-led evaluation of teacher professional development. Professional Development in Education, 45(2), 1-18. 
[21] Muijs, D. (2012). Methodological change in educational effectiveness research. In: C. Chapman, P. Armstrong, A. Harris, D. Muijs, \& P. Sammons. (Ed.), School Effectiveness and Improvement Research, Policy and Practice (pp. 72-80). Abingdon: Routledge.

[22] Nitecki, E. (2015). Integrated school-family partnerships in preschool: Building quality involvement through multidimensional relationships. School Community Journal, 25(2), 195-219.

[23] Oleson, A., \& Hora, M.T. (2014). Teaching the way they were taught? Revisiting the sources of teaching knowledge and the role of prior experience in shaping faculty teaching practices. Higher Education, 68(1), 29-45.

[24] Pianta, R. C., La Paro, K. M., Payne, C., Cox, M. J., \& Bradley, R. (2002). The relation of kindergarten classroom environment to teacher, family, and school characteristics and child outcomes. The elementary school journal, 102(3), 225-238.

[25] Qin, X., \& Yang, Y. (2012). The exploration on kindergarten teacher professional development's "self-study" model. Teacher Development, 29(5), 29-33.

[26] Rentzou, K., \& Sakellariou, M. (2011). Greek pre-service kindergarten teachers' beliefs about and practices of developmentally appropriate practices in early childhood education. Early Child Development and Care, 181(8), 1047-1061.

[27] Savas, A. C. (2012). The Contribution of School-Family Cooperation on Effective Classroom Management in Early Childhood Education. Educational Sciences: Theory and Practice, 12(4), 3099-3110.

[28] Spodek, B. (1973). Needed: A new view of kindergarten education. Childhood Education, 49(4), 191-197.

[29] Thomas, R. M. (2003). Blending qualitative and quantitative research methods in theses and dissertations. Thousand Oaks: Corwin Press.

[30] Timperley, H., Wilson, A., Barrar, H., \& Fung, I. (2008). Teacher professional learning and development. International Academy of Education. Retrieved May 3, 2018, from http:/ / edu.aru.ac.th/ childedu/images/PDF/benjamaporn/EdPractices_18.pdf

[31] Vlasov, J., \& Hujala, E. (2017). Parent-teacher cooperation in early childhood educationdirectors' views to changes in the USA, Russia, and Finland. European Early Childhood Education Research Journal, 25(5), 732-746.

[32] Wang, M., Hong, X. M., \& Pang, L. J (2015). Early childhood education teachers in private kindergartens of China: problems, influentials, and suggestions. Studies in Teacher Education, 3, 7.

[33] Zhang, X., \& Wong, J. L. (2018). How do teachers learn together? A study of school-based teacher learning in China from the perspective of organisational learning. Teachers and Teaching, 24(2), 119-134.

[34] Zhou, X. (2016). Optimizing the teacher education mechanism for teachers in rural China. Teacher in China, 20, 1-10. 